\title{
Physician safety in work place
}

(BIRDEM Med J 2020; 10(1): 1-6)

The Health and Safety Executive define violence as 'any incident in which an employee is threatened or assaulted by a member of the public in circumstances arising out of the course of his/her employment' of all work settings, medical sites carry the greatest risk to staff of verbal abuse and threats. Physicians in emergency medicine, psychiatrists and those involved with primary care are at increased risk of violent acts from patients and families.

The World Medical Association (WMA) is noting a rising tide of violence against physicians and health professionals being reported to it from around the globe. Physician leaders from Central and South America, from India and Bangladesh, and from Germany have all recently reported incidents of physicians being assaulted and even killed. Now the WMA is calling for security posts to be provided in all healthcare facilities to combat the incidents of violent attacks against healthcare professionals and facilities. WMA President said: "Violence has become a significant public health challenge. Attacks on healthcare facilities, healthcare personnel, and the sick and wounded are in direct breach of medical ethics, international humanitarian and human rights laws."

\section{Incidence worldwide}

Social media portrays almost one incidence of violence against doctors every couple of days, which goes viral instantly. Violence against doctors is not only localized to the Indian subcontinent, but also rather prevalent throughout the world. Earliest studies of violence against doctors from the USA date back to the 1980s and in the US the rate of violence is even higher. Between the years 1980-1990, 106 healthcare workers died as a result of violence: 27 pharmacists, 26 physicians, and 53 nurses. Seventy percent of the physicians and $90 \%$ of the support staff working in a hospital emergency room in Israel reported violent acts, mostly verbal abuse where $57 \%$ of emergency care workers have been threatened with a weapon, whereas in the UK, $52 \%$ of doctors reported some kind of violence. In Asia, violence against medical professionals has been reported from China, Israel, Pakistan, and Bangladesh, and prevalence rates have been higher when compared to those of Western countries. The Indian Medical Association suggests that up to $75 \%$ of doctors have faced some kind of violence at work, which is similar to the rates from other countries in the continent. This violence may comprise telephonic threats, intimidation, verbal abuse, physical but noninjurious assault, physical assault causing simple or grievous injury, murder, vandalism, and arson.

The Lancet has helped bring global attention to the problem of violence against doctors in China through its Editorials in 2012 and 2014 and has stimulated local discussion on potential solutions. India's health system faces a similar crisis and the magnitude of the Indian problem is, perhaps, greater. More than 2000 junior doctors from 17 government-run hospitals in India's largest city, Mumbai, went on strike for 4 days in March, 2017 , to protest a recent spate of violence against doctors. At least four separate incidents of assault on a junior doctor at a government hospital were reported in the week preceding the strike in the state of Maharashtra of which Mumbai is the capital. The chief demand of the striking doctors was better security from the government to protect them at hospitals. Violence against doctors in India is not new, and a 2015 survey by the Indian Medical Association suggests that as many as $75 \%$ of doctors in India have faced some form of violence at work. Each state in India has the right to enact its own laws related to health care. An incident in February, 2017, in Kolkata, West Bengal, India, where a private hospital was vandalised by an irate mob following the death of a patient due to alleged medical negligence led to the state government rapidly introducing a new law. ${ }^{7}$ The law enforces far more severe financial and regulatory penalties than currently in place, including the possibility 
of criminal prosecution of doctors for medical negligence in private hospitals, and imposes direct price controls on private health services in the state. In a survey of 720 primary care physicians in Canada, nearly one-third of respondents had been exposed to aggressive behaviour from a patient $(90 \%)$ or patient's family (70\%) in the previous month. Nearly all reported having at least one abusive incident during their career; threequarters of those were major incidents (e.g., sexual harassment), whereas 39\% were severe (e.g., assault, sexual assault or stalking). Many physicians, nurses and other health workers experience violence in the workplace. A patient in a psychiatric unit savagely assaults a doctor in British Columbia, leaving him with severe facial injuries, a broken jaw and other fractures. ${ }^{1}$ This is an extreme case but not an isolated incident. More than $70 \%$ of doctors in Australia experienced verbal or written aggression and almost a third experienced physical aggression. Higher proportions of hospital non-specialists and specialists-in-training experienced aggression from patients, patient relatives or carers and co-workers. Higher proportions of female doctors experienced verbal or written aggression from patient relatives or carers and co-workers. It was found that majority $(85 \%)$ of the physicians has faced mild events, $62 \%$ have faced moderate events and roughly $38 \%$ were subjected to severe violence. Some physicians revealed more than one form of aggression being faced by them in 12 preceding months which makes the collective percentage greater than $100 \%$. Verbal abuse is the most frequent type of mistreatment faced by the doctors from the patients or their attendants.

Fact is violence against doctors at their workplace is not a new phenomenon. However, in recent times, reports of doctors getting thrashed by patients and their relatives are making headlines around the world and are shared extensively on social media. Almost every doctor is worried about violence at his/her workplace, and very few doctors are trained to avoid or deal with such situations.

\section{Risk factors for violences}

An Indian study of risk factors associated with violence against doctors found the following: 1. younger doctors face more physical violence 2 . female doctors are more likely to face violence 3 . department of obstetrics and gynecology reported the highest rates of violence, followed by the medicine department with allied specialties, and surgery with allied specialties. ${ }^{4}$ Verbal violence was the most common form of violence. ${ }^{5}$ In the emergency department, $100 \%$ of doctors reported some kind of verbal violence.

The same study also showed the top perceived causes for violence to be long waiting periods, delay in medical attention, and denial of admission, among other factors.

\section{Effect of violence on medical professionals}

Medical professionals who faced violence have been known to develop psychological issues such as depression, insomnia, post traumatic stress, fear, and anxiety, leading to absenteeism. Many have lost their clinics, injured themselves, lost lives, and also tarnished their reputation as a professional due to these incidents. Regarding the cause of this under reporting, various explanations exist. Some doctors do not even know what constitutes aggressive behaviour. Some other factors such as lack of time, reluctance to fill informs, and fear of being blamed for incidents also can be considered. Some doctors feel coping with aggression as part of the job and some feel too guilty or embarrassed to report events. A study in Israel showed that the most common causes of violence were long waiting time $(46.2 \%)$, dissatisfaction with treatment $(15.4 \%)$, and disagreement with the physician (10.3\%). The scenario in Indian subcontinent is not so bright. Doctors are frequently assaulted in India as well where doctors are shot, even stabbed. Studies from around the world show that acts of violence have a negative effect on the physician's family life and quality of life. In the study conducted in Kuwait $86 \%$ of the physicians who experienced violence reported that it caused insomnia, depressions and other effects. A study in Israel showed that $36.2 \%$ of the community based physicians reported a negative impact on their family life and quality of life who were victims of violence. Those who were victims of aggression had a change in behaviour. Among the coping strategies among GPs included increasing prescribing, referring threatening patients to secondary care services and taking threatening patients off their lists. Among hospital doctors $27 \%$ reported that their approach to work was changed due to violence or the fear of violence, although the nature of this change was not acceptable. Violence against physicians is associated with increased stress, alcohol consumption and risk of 
developing mental health problems, including depression, anxiety and suicidal ideation. It may also result in absences, physical problems, quitting or refusing to work in high-risk areas, and compromised patient care. In the Canadian survey, three-quarters of those who had an abusive encounter in the previous month did not seek help, and $64 \%$ did not report the incident. More than half were not aware of any policies to protect them. Because some of the perpetrators have psychosis, addiction problems or dementia, physicians may view violence as a part of the patient's medical condition

\section{Possible explanation for agitation and violences:}

Patient dissatisfaction-as might be expected-is the proximate cause, agitated friends and relatives accompanying patients are the usual perpetrators, and accident and emergency, intensive care unit, and postsurgical wards are the most common settings for such violence. However, violence against doctors perpetrated by patient escorts is a superficial sign of a deeper systemic failure. Reactionary measures, such as enhanced security at government hospitals or harsh medical negligence laws, are unlikely to boost the flagging morale of the medical workforce or represent sustainable solutions for the delivery of safe, effective, low-cost, and truly universal health care in the long term.

Superspeciality $>$ Primary care physicians: Since the 1970s, medical education in India has increasingly emphasised specialisation over general practice, and it is now common for patients with relatively minor conditions to be treated in the first instance by specialists at tertiary hospitals. Paradoxically, the paucity of new investment in an ever-eroding primary care infrastructure has meant that patients who could have been diagnosed in the earliest stages of their disease often slip through the primary care net to present at the same tertiary hospitals with advanced and frequently incurable disease. This issue has led to an overburdened tertiary health system for which triage is routine. Consequently, the duration of each patient encounter is invariably brief, particularly in government hospitals, and does not afford the doctor - particularly the trainee doctor - the scope to develop a meaningful doctorpatient relationship. The tenuous relationship that does develop is especially susceptible to breaking down into violence when the financial implications of care are discussed in India where each year an estimated 60 million patients are forced to pay out of their own pocket for drugs and surgical procedures that they are in no position to afford.

Working conditions: In India and Bangladesh long waiting times, physician shortages, limited resources and stress may also contribute to the problem.. Canadian physicians working in hospital and psychiatric emergency departments, and after-hours clinics have an increased chance of an abusive encounter, as do clinicians making house calls and those who treat large numbers of patients with mental illness and addiction problems. A survey of about 700 family physicians in the United Kingdom reported that female and male doctors are at equal risk. However, it is not known if the same holds true in Canada.

\section{Causal factors of violence}

\section{Policy factors}

Bangladesh health-care spending is close to $2.7 \%$ of the total budget, which is dismal when compared to other countries. Though an extensive network of health service has been established. The health service remains relatively low in Bangladesh although we have improved economy recently as poverty (31\% at 2010) levels have decreased. Our government's share in the health-care delivery is around $7.9 \%$, citizens pay most of their health care bill as the out of pocket expenditure as a percentage of private expenditure on health is $96.5 \%$. The most dominant role in the health-care delivery is provided by small hospitals having up to thirty beds, but here, with no insurance penetration. As a result of this, small medical establishments are particularly susceptible to violence and aggression at the time of billing. Even government hospitals are not spared of violence due to poor availability of facilities, which is highlighted by the fact that we have only 3 hospital beds per 10,000 peoples. Doctors to population ratio is 1:2000 and nurse to population is 1:5000. This translates to long working hours and poor work environment for doctors and staffs which makes them susceptible to making mistakes and prone to violence.

\section{Social factors}

Traditionally in Banggladesh, medical professionals have been treated with respect by the society. However, the present impression of profit making of few in the profession has crippled the image of the doctors. With the advent of modern medicine, the cost of health care 
has increased globally, but due to low literacy rates, there is an unrealistic expectation that paying more money should save one's life, i.e., better outcomes are expected even for risky procedures. While a doctor may receive only $20 \%$ of the total amount, it is his/her decisions that determine the total expenses. This, coupled with so many sensational news reports of doctors overcharging for various tests and reports of violence in the media, has led the common man to believe that it is but natural for a doctor to write excessive tests to earn money. The public feels that media shows so many doctors getting beaten up every day and perpetrators are never shown punished, so perhaps, they can take the matter into their own hands when they feel cheated by a doctor.

\section{Professional factors}

As part of the medical curriculum, all doctors are taught clinical behavior but not all are taught empathy. Whereas in clinical practice, effective patient-doctor communication involving receiving an explanation for the occurrence of the symptom/sign, likely duration of treatment, the lack of unmet expectations, and empathy are associated with overall patient satisfaction with the services. Many a time, the patient does not comprehend the gravity of the situation and expects a better chance of complete recovery due to improper explanation by the treating doctor. In a country like Bangladesh, due to the scarcity of doctors and health-care facilities, these issues are seldom given importance, which makes this one of the important causes of rising violence against health-care practitioners in the country. Statistics from a recent Indian study of 151 doctors, evaluating workplace violence, suggested that only six of them had received some formal training in effective communication and five of these doctors belonged to psychiatry department where it is a part of the curriculum. This suggests that there is an urgent need for improving the communication between the patient and doctor by imparting training to the current generation of doctors.

\section{Local factors}

Certain local factors such as mob mentality and politicians play an important role in inciting violence which frequently develops into crisis in hospitals. Death of a loved one is often used by the local politicians as a show of strength by ransacking and damaging hospital's property. This problem is very common in small primary health centers which lack facilities and where even trivial problems cannot be dealt with properly, but when doctors deny the availability of these facilities, they are faced with threats and intimidation to treat at any cost by the local politicians who are involved by patients' relatives, often even. This, combined with almost a complete lack of security in government hospitals, primary health centers, and community health centers, makes these highly susceptible to mob attacks.

\section{Solutions}

In a new policy statement, the WMA says that although many countries accept the need for violence prevention programs they still face many challenges. These include inadequate or non-existent reporting of data, inadequate investment in prevention programs and support services for victims of violence, and failure to enforce existing laws against violence. These failures are to do with a lack of leadership, and social determinants such as unemployment, poverty, health, gender inequality, and poor access to educational opportunities. So, WMA in their 2019 position statement proposed a series of measures, including the provision of security posts and efficient surveillance in all healthcare facilities. It is time that governments demonstrated their political commitment to tackle the shame of violence on our health services.

Part of the solution to reducing workplace violence for physicians lies in research. Most applicable research is old and quantifies the problem rather than exploring causal factors, risk reduction and we need standard methods of evaluating the efficacy of protocols for everything from documentation to support, plus preventive measures such as flagging systems and training.

There are many programs that purport to address workplace violence, but few have been validated. One exception is the four-day Omega education and training program that has been delivered to over 47000 Canadian mental health care workers. A study of the intervention showed that it bolstered confidence in dealing with patient aggression, and reduced exposure to minor and serious violence. ${ }^{7}$

Some physicians have suggested amending the Criminal Code of Canada to make it a specific criminal offence to assault health care workers performing their duties, 
similar to what currently exists for police officers and public transit operators. This was proposed and agreed to in 2015 (and again in 2016) in motions at the Canadian Medical Association's General Council. The association is drafting a letter to the federal minister of justice with suggested wording. At least 30 American states have made it a felony to assault hospital workers. Does this deter attackers? No one has measured it.National regulatory and professional medical bodies, such as provincial colleges, could also provide leadership in talking about the problem, reducing stigma and encouraging strong action. Physicians should speak out to their chiefs of staff, their colleges and, when warranted, the police. Workplace violence is not part of their job.

Doctors should utilize this crisis as an opportunity to come together with their patients to demand greater nationwide political commitment to address the underlying social determinants of violence against doctors.

\section{Prevention of violence against doctors}

Due to the rising rates of violence, doctors are reluctant to take up serious cases, compromising health-care delivery. Thus, there is an urgent need to make healthcare facilities safe places for doctors as only then can they work with complete dedication. This needs to be done at various levels by the government, media, and medical professionals alike.

\section{Responsibility of the government}

As the saying goes, "health is wealth." Policymakers need to understand that the overall health of the people contributes to the efficiency of the workforce, in turn, contributing to the growth of the economy. More health budget spending would translate to better facilities and increased doctor-patient ratio, leading to a decrease in violence related to these factors. Furthermore, there is an attempt by relatives to allege negligence in cases of sudden death of a patient; this leads to first investigation reports being lodged for murder, culpable homicide, and cheating many a time. This practice needs to be discouraged by making legal provisions deterring relatives from doing so unless evidence is present. There have been attempts by the state government to make laws to prevent violence against doctors, and the first such law came into existence in Andhra Pradesh,india during the tenure of Chief Minister YS Raj Shekhar
Reddy in 2007 who was a doctor himself. The law stated that any violence against doctors would be treated as a nonbailable offense with a penalty of up to 50,000 rupees and a jail term of up to 3 years. This was followed by states such as Delhi, Haryana, Rajasthan, Tamil Nadu, Odisha, and others, making such acts for prevention of violence against doctors. In total, 19 states of India have some kind of act for protection of medical professionals and health-care establishments. However, inquiries into its effectiveness in the states of Punjab and Haryana have revealed that very few cases have reached courts after filling of a challan, but no person accused of assault on a medical professional or hospital has yet been penalized under the said acts till 2015. Thus, the law needs to be enforced strictly along with the deployment of adequate security personnel in government hospitals to ensure a safe workplace for doctors.

\section{Responsibility of media}

Doctors are almost always portrayed negatively by the media. There are sensational news reports of death and sting operations against doctors. Media needs to understand that the practice of medicine is not a blackand-white subject. Diagnosis of a patient is essentially a hypothetico-deductive process, and with the appearance of new evidence through investigations and knowledge, the diagnosis of some of the cases continues to be questioned and refined. However, whatever the diagnosis be, there is always a risk of negative outcomes. Doctors cannot be held accountable for every death that occurs in the hospital on account of negligence.

\section{Responsibility of institutions}

If violence occurs despite taking all precautions, it is important for the institution to protect the doctors involved, but at the same time not meet anger with anger. A standard operating procedure may be developed for such situations like Code Purple used worldwide to alert medical staff to potential violence. It includes the following measures to be taken in case of violence:

a)An announcement on the hospital's public address system, giving the exact location of violence to disseminate the information. A distinct siren may also be installed to alert everyone in case violence occurs b)Security staff to respond immediately and assist if needed c)All the staff except that of intensive care unit and operation theater to come to aid and form a human chain around the professional under threat. The 
personnel involved in the chain need to remain calm and avoid any altercation which may escalate the situation d) A senior member of staff not involved in treatment may try to communicate with the patient's relatives and try de-escalating the situation e) All the members of staff to practice restraint and not lose their control f) Once the situation is under control, an announcement on the public address system should be made. g) The practice of this drill should be done monthly in every medical establishment.

Apart from this, all medical institutions should have closed circuit televisons installed and have a zero tolerance to workplace violence. Such steps have been taken already in countries like the UK and Australia where there is mandatory organizational and police reporting of violent acts. Perhaps, we need a social shift toward a culture that does not accept that violence is necessary or an unavoidable component of behavior

\section{Responsibility of the doctors}

Modern medicine is reaching new frontiers, but at the same time, a negative public perception of doctors is leading to an increase in litigations. Thus, every doctor should follow the cardinal principle do not overreach, i.e., do not treat beyond the scope of one's training and facilities to prevent both violence and litigations against themselves. Second, all doctors should ensure that a valid and informed consent is taken properly and not just considered a formality. Extra efforts should be taken to explain the condition to the relatives because healthcare literacy is low in the country. Thus, training on effective communication needs to be imparted to every medical professional which should include assertiveness training, refusal skills, anger management, and stress management. Psychiatrists should be actively involved in such workshops for the benefit of medical professionals. Apart from all these steps, it is important to be vigilant and look for early warning signs of violence by using the STAMP approach as follows:

Staring is an early indicator of potential violence. Nurses have felt that staring was used to threaten them into a quicker response and when they responded to this, violence tended to be avoided

Tone and volume of voice have been associated with violent episodes. Most instances involved raised voices and yelling, but some also involved sarcastic and caustic replies.Anxiety in many people who attend the emergency department can make the visit stressful. Doctor should intervene before the anxiety reaches dangerous levels, but sometimes, the patient's anxiety does escalate to violence. Mumbling is a cue for violence as it suggests mounting frustration $P$ acing by relatives has been observed in instances that resulted in violence and is seen as an indication of mounting agitation. So even after taking all these steps, things still can go wrong.In that case we cannot but agree with,P Madhok who wrote. There is something to be said for young doctors who should learn martial arts. The world is increasingly progressing towards violence. So karate,taekondo and other martial arts are worthwhile learning for self defense. It will boost the doctor's confidence even if not used.

\section{References}

1. May 20,2017 The lancet editorial

2. www.cmaj.ca/site/misc/cmaj_staff.xhtml

3. https://www.banglajol.info/index.php/JOM/article/download/ $5465 / 4271$ 